\title{
Characteristics of flour and dough from purple and blue wheat grain
}

\author{
Iva Burešová, Václav Trojan, Martin Helis
}

\begin{abstract}
The characteristics of flours and doughs prepared from wheat grains containing purple pericarp (variety PS Karkulka and Jumiko) and wheat grain containing blue aleurone (variety Skorpion) were tested and compared with commercial wheat to evaluate the applicability of colored wheat in bread making. The fine flours prepared from colored wheat grains significantly differed in the activity of the amylase enzyme, expressed as Hagberg falling number. Zeleny sedimentation volume of flour prepared from grains of the PS Karkulka variety $(36 \mathrm{~mL})$ was significantly higher than the values of AF Jumiko and Skropion $(34 \mathrm{~mL})$ varieties. The results of uniaxial deformation test indicated that doughs prepared from wheat varieties PS Karkulka and Skropion can be elongated; the dough is, however, weak and can be expected to rupture more easily than dough prepared from variety AF Jumiko, as well as commercial flour. Even if some variations in the values of farinographic dough development time and stability were also observed, clear differences in the behavior of doughs prepared from colored and commercial flours were not found. The differences in dough behavior during heating test were also negligible. It can be concluded that none of the tested colored wheat grains exhibited characteristics completely different from the others or the commercial one. The results may indicate the applicability of all tested colored wheat grains in yeast-leavened bread production.
\end{abstract}

Keywords: fine flour; rheology; quality; bread making

\section{INTRODUCTION}

Wheat is grown on more land than any other commercial crop and continues to be the most important food grain source for humans. Global production is about 700 million tons per year. Wheat provides $20 \%$ of daily protein and is a significant source of calories for 4.5 billion people (FAO, 2014). The unusual properties of wheat storage proteins (gluten proteins) allow flour to be transformed into dough with suitable properties for bread making (Goesaert et al., 2005).

Wheat grain may also be a good source of phytochemicals, compounds with health-promoting effects. When taken regularly and in adequate amounts, these molecules can have long-term benefits on human health through reducing the likeliness of obesity, diabetes, and cancer and degenerative diseases, such as cardiovascular disease (Borrelli and Trono, 2016). Some of these phytochemicals significantly influence grain color. Anthocyanins are accumulated in the aleurone or pericarp layer resulting in or a combination of blue and purple. Phlobaphenes present mainly in the outer layer are responsible for a reddish color (Lachman et al., 2018).

Colored wheat grains can be used in food production. Since the phytochemicals are situated in the aleurone or pericarp layer, whole grain products are preferred. The applicability of purple wheat grain in biscuit and pasta production has already been studied. Biscuits prepared from whole wheat extracted from purple grains exhibited higher antioxidant activity than biscuits prepared from common wheat grain. Purple biscuits, moreover, showed lower levels of lipid-derived carboxylic acids and higher levels of alcohols and aldehydes than common biscuits, indicating lower oxidative degradation of lipids (Pasqualone et al., 2015).

Ficco et al. (2016) found the sensory properties of pasta from the purple genotype not to be significantly different from commercial whole wheat pasta. In vitro glycemic index was also lower.

Wheat grain with purple pericarp (PS Karkulka and Jumiko) and wheat grain with blue aleurone (Skorpion) (Lachman et al., 2018; Martinek et al., 2013) were studied. The aim of this study was to compare the characteristics of flour and dough prepared from colored wheat grain with commercial wheat flour and dough, and to evaluate the applicability of these wheats' grains in the production of yeast-leavened bread.

\section{Scientific hypothesis}

The doughs prepared from colored wheat grains exhibit different behavior than dough made from commercial wheat during uniaxial deformation, farinographic and heating tests, which may limit their use in the production of yeastleavened bread production. 


\section{MATERIAL AND METHODOLOGY}

\section{Material}

Fine flours from wheat grain with purple pericarp (PS Karkulka and Jumiko) and wheat grain with blue aleurone (Skorpion) were used in this study. Fine flours are characterized by being made up of at least $96 \%$ of particles that pass through a $257 \mu \mathrm{m}$ sieve opening and a maximum of $75 \%$ of particles passing through a $162 \mu \mathrm{m}$ sieve opening (Decree No. 333/1997). The Babiččina volba commercial fine flour manufactured by GoodMills Česko s.r.o. was bought in a local supermaket.

\section{Flour characteristics}

The flours were characterized by Hagberg falling number and Zeleny sedimentation volume. Hagberg falling number is used to describe the activity of flour amylase enzymes. It was determined according to ČSN EN ISO 3093 (2011). Zeleny sedimentation volume is a key factor of the wheat quality. It is used to predict the baking strength of flour. This parameter was determined according to ČSN EN ISO 5529 (2011).

\section{Dough rheological characteristics}

Uniaxial deformation test was performed on dough samples made by mixing flour, water (according optimal farinograph water absorption) and salt (1.5\%). The dough was made into thin rolls, put onto the lubricated surface of a Teflon mold and compressed with a lubricated top plate. Test pieces were formed into $5 \mathrm{~cm}$ long chunks with a trapezoidal cross-section $(3 \mathrm{~mm}, 5 \mathrm{~mm}, 4 \mathrm{~mm})$. The doughs were left resting for $40 \pm 1 \mathrm{~min}$ at $30 \pm 1{ }^{\circ} \mathrm{C}$. The test was performed using textural analyzer TA.XT plus (Stable Micro Systems, UK) equipped with an SMS/Kieffer Dough and Gluten Extensibility Rig. During testing the dough sample was stretched by the hook until it fractured. Test speed of the hook was $3.00 \mathrm{~mm} \cdot \mathrm{s}^{-1}$, trigger force $5 \mathrm{~g}$. The force required to stretch the dough sample and the displacement of the hook were recorded as a function of time. The values of resistance to elongation $R$ $(\mathrm{N})$, extensibility $E(\mathrm{~mm})$ and extension area $A$ (N.mm) were calculated. Force $R$ represents the dough resistance to extension, extensibility $E$ represents the distance at which this peak force occurs, and extension area $A$ is the area under the curve which is related to the energy required to stretch the test piece to its rupture. Each test was performed on dough samples prepared at least in six replicates. The given results are represented as mean values.

Dough behavior during mixing was studied using Mixolab (Chopin Technologies, Paris, France). The dough was prepared by mixing flour with distilled water. Chopin $\mathrm{S}$ protocol simulated the operation conditions of the Farinograph. The obtained parameters were: flour water absorption WA (\%), dough development time $D T(\mathrm{~min})$, dough stability $S T$ ( $\mathrm{min}$ ) and degree of softening $D S$ (FU). The standard Chopin+ protocol was used to test dough behavior during heating and cooling, following a $30-90-50^{\circ} \mathrm{C}$ pattern. The extent of dough weakening $\alpha$ $\left(\mathrm{Nm} \cdot \mathrm{min}^{-1}\right)$, starch gelatinization $\beta\left(\mathrm{Nm} \cdot \mathrm{min}^{-1}\right)$ and cooking stability $\gamma\left(\mathrm{Nm} \cdot \mathrm{min}^{-1}\right)$ were evaluated. Each test was performed on dough samples prepared at least in six replicates. The given results are represented as mean values.

\section{Statistical analysis}

The results were statistically analyzed using analysis of variance (ANOVA). The differences were tested on $p=0.05$ significance level using Fisher LSD test. The analysis was performed using Statistica 13 software (StatSoft, CR).

\section{RESULTS AND DISCUSSION}

\section{Flour characteristics}

The flours were characterized by Hagberg falling number and Zeleny sedimentation volume (Table 1). The flour prepared from Skorpion variety was the only one exhibiting optimal value (251 s) for bread making (Kurt and Evers, 2017). The flours from the AF Jumiko and PS Karkulka varieties exhibited significantly $(p<0.05)$ higher values (407 - 460 s), indicating low activity of amylase enzymes (Ranken, Kill and Baker, 1997). Zeleny sedimentation volume of flour prepared from grains of PS Karkulka variety $(36 \mathrm{~mL})$ was significantly $(p<0.05)$ higher than the values of AF Jumiko and Skropion ( $34 \mathrm{~mL}$ ) varieties. This higher value of sedimentation volume can be explained by better swelling and flocculating properties of the insoluble proteins associated with good bread making characteristics (Kurt and Evers, 2017).

\section{Dough behavior during uniaxial deformation}

Dough extensibility $E$ did not significantly $(p<0.05)$ differ among the tested doughs (Table 2). Dough resistance to elongation $R$ was significantly lower in doughs prepared from colored wheat grain $(0.17-0.30 \mathrm{~N})$ than in the dough from commercial wheat flour $(0.34 \mathrm{~N})$. The recorded weak resistance to extension can also be related to the decrease in the extension area values $A$ recorded in dough from colored wheat flours. The decrease was, however, significant $(p$ $<0.05)$ only in the dough prepared from Skorpion variety. The combination of good resistance to elongation and extensibility, expressed as $R / E$ ratio, is expected in doughs with good bread making quality (Burešová and Hřivna, 2011; Goesaert et al., 2005; Tsiami et al., 1997a, b). The dough prepared from AF Jumiko variety exhibited an $R / E$ ratio similar to dough from commercial flour. The values obtained in dough from PS Karkulka and Skorpion varieties were significantly $(p<0.05)$ lower. Significantly weak resistance to extension recorded in these samples can be the factor decreasing the values of $R / E$ in these doughs. The results of uniaxial deformation test indicated that doughs prepared from PS Karkulka and Skropion varieties can be elongated; these doughs are, however, weak, and can be expected to rupture more easily than doughs prepared from AF Jumiko variety, as well as commercial flour.

\section{Farinographic characteristics}

Farinographic characteristics are used to describe dough formation and behavior during kneading at constant temperature. The amount of water required to prepare dough with optimal consistency of $500 \mathrm{FU}$, expressed as water absorption, is also obtained. 
Table 1 Hagberg falling number $(F N)$ and Zeleny sedimentation volume (SEDI) of flours from colored wheat grains.

\begin{tabular}{lcc}
\hline \multicolumn{1}{c}{ Flour } & FN & SEDI \\
& $(\mathbf{s} \pm$ SD $)$ & $(\mathbf{m L} \pm$ SD $)$ \\
\hline AF Jumiko & $460 \pm 10^{\mathrm{c}}$ & $34 \pm 2^{\mathrm{a}}$ \\
PS Karkulka & $407 \pm 9^{\mathrm{b}}$ & $36 \pm 2^{\mathrm{b}}$ \\
Skorpion & $251 \pm 3^{\mathrm{a}}$ & $34 \pm 2^{\mathrm{a}}$ \\
\hline
\end{tabular}

Table 2 Dough behavior during uniaxial deformation test.

\begin{tabular}{|c|c|c|c|c|}
\hline Flour & $\begin{array}{c}\mathbf{R} \\
(\mathbf{N} \pm \mathbf{S D})\end{array}$ & $\begin{array}{c}\mathrm{E} \\
(\mathrm{mm} \pm \mathrm{SD})\end{array}$ & $\begin{array}{c}\text { A } \\
(\text { N.mm } \pm \text { SD })\end{array}$ & $\begin{array}{c}\mathrm{R} / \mathrm{E} \\
\left(10^{-3} \text { N.mm }\right. \\
\end{array}$ \\
\hline AF Jumiko & $0.30 \pm 0.04^{\mathrm{c}}$ & $44 \pm 9^{a}$ & $9.9 \pm 0.7^{\mathrm{ab}}$ & $7.0 \pm 0.9 b$ \\
\hline PS Karkulka & $0.21 \pm 0.02^{\mathrm{b}}$ & $56 \pm 9^{a}$ & $9.2 \pm 0.9^{\mathrm{ab}}$ & $3.8 \pm 0.7 \mathrm{a}$ \\
\hline Skorpion & $0.17 \pm 0.04^{\mathrm{a}}$ & $47 \pm 9^{\mathrm{a}}$ & $8.2 \pm 0.7^{a}$ & $3.6 \pm 0.6 \mathrm{a}$ \\
\hline Commercial & $0.34 \pm 0.03^{\mathrm{d}}$ & $52 \pm 9^{\mathrm{a}}$ & $12.4 \pm 0.9^{b}$ & $6.5 \pm 0.9 b$ \\
\hline
\end{tabular}

Note: Dough resistance to elongation $(R)$, extensibility $(E)$, extension area $(A), R / E$ ratio.

Table 3 Rheological characteristics of dough.

\begin{tabular}{lcccc}
\hline \multicolumn{1}{c}{ Flour } & $\begin{array}{c}\text { WA } \\
(\% \pm \text { SD) }\end{array}$ & $\begin{array}{c}\text { DT } \\
(\mathbf{m i n} \pm \text { SD })\end{array}$ & $\begin{array}{c}\text { ST } \\
(\mathbf{m i n} \pm \text { SD) }\end{array}$ & $\begin{array}{c}\text { DS } \\
(\text { FU } \pm \text { SD })\end{array}$ \\
\hline AF Jumiko & $60.0 \pm 0.4^{\mathrm{b}}$ & $4.9 \pm 0.3^{\mathrm{b}}$ & $36 \pm 2^{\mathrm{b}}$ & $46 \pm 7^{\mathrm{a}}$ \\
PS Karkulka & $61.4 \pm 0.4^{\mathrm{c}}$ & $3.6 \pm 0.4^{\mathrm{b}}$ & $28 \pm 1^{\mathrm{a}}$ & $44 \pm 3^{\mathrm{a}}$ \\
Skorpion & $62.4 \pm 0.8^{\mathrm{d}}$ & $1.0 \pm 0.4^{\mathrm{a}}$ & $39 \pm 5^{\mathrm{b}}$ & $38 \pm 9^{\mathrm{a}}$ \\
Commercial & $57.6 \pm 0.5^{\mathrm{a}}$ & $2.9 \pm 0.1^{\mathrm{ab}}$ & $29 \pm 1^{\mathrm{a}}$ & $44 \pm 5^{\mathrm{a}}$ \\
\hline
\end{tabular}

Note: Farinographic water absorption (WA), dough development time (DT), dough stability (ST) and degree of softening $(D S)$.

Table 4 Rheological characteristics of dough. Mixolab dough weakening $(\alpha)$, gelatinization rate $(\beta)$ and stability $(\gamma)$.

\begin{tabular}{|c|c|c|c|}
\hline Flour & $\begin{array}{c}\alpha \\
\left(10^{-3} \mathrm{Nm} \cdot \mathrm{min}^{-1} \pm \mathrm{SD}\right)\end{array}$ & $\begin{array}{c}\beta \\
\left(\mathrm{Nm} . \mathrm{min}^{-1} \pm \mathrm{SD}\right)\end{array}$ & $\begin{array}{c}\gamma \\
\left(\mathrm{Nm} . \mathrm{min}^{-1} \pm \mathrm{SD}\right)\end{array}$ \\
\hline AF Jumiko & $-69 \pm 9^{a}$ & $0.09 \pm 0.05^{\mathrm{a}}$ & $-0.07 \pm 0.02^{\mathrm{a}}$ \\
\hline PS Karkulka & $-113 \pm 9^{a}$ & $0.39 \pm 0.02^{\mathrm{ab}}$ & $-0.06 \pm 0.03^{a}$ \\
\hline Skorpion & $-94 \pm 6^{\mathrm{a}}$ & $0.48 \pm 0.06^{\mathrm{b}}$ & $-0.08 \pm 0.01^{\mathrm{a}}$ \\
\hline Commercial & $-57 \pm 4^{a}$ & $0.22 \pm 0.09^{\mathrm{ab}}$ & $-0.05 \pm 0.04^{\mathrm{a}}$ \\
\hline
\end{tabular}

The water absorption WA of all tested flours prepared from colored wheat grain was significantly $(p<0.05)$ higher than the absorption of commercial flour (Table 3). Dough development time DT was significantly higher in dough prepared from AF Jumiko and PS Karkulka varieties than in dough from Skorpion and commercial flour. Dough stability ST of dough prepared from PS Karkulka was closer to the commercial flour. The stability of dough ST prepared from PS Karkulka and AF Jumiko was, however, significantly $(p<0.05)$ higher. Dough softening DS did not differ among tested flours. The farinographic test revealed that the flours from colored wheat required a higher amount of added water to reach optimal consistency of $500 \mathrm{FU}$. Even if some variations in dough development time and dough stability were also observed, clear differences in the behavior of doughs prepared from colored and commercial flours were not found.

\section{Dough behavior during heating}

Changes of dough viscosity during baking significantly impact dough ability to trap and hold gas in enclosed cells and expand along with it. Thus, optimal dough viscosity is essential for obtaining high quality, spongy bread crumb (Collar, Bollain and Rosell, 2007; Mondal and Datta,
2008). Viscosity changes occurring in dough during baking are generally attributed to protein breakdown, gelatinization rate and cooking stability.

At the beginning of heating $\left(30-50^{\circ} \mathrm{C}\right)$, doughs exhibited weakening indicated by negative values of $\alpha$ (Table 4). Dough weakening can be partially related to water released from proteins after reaching the temperature of their denaturation, and partially to water released from dough macromolecules due to mechanical stress applied on the sample. Dough viscosity rose in the temperature range of 60 $-80{ }^{\circ} \mathrm{C}$, which is evident from positive values of $\beta$, indicating dough strengthening. While in the previous phase of heating, the dough characteristics were mainly affected by protein denaturation, starch gelatinization occurred in this heating phase. Light dough weakening was observed during the final phase of the heating test, which is evident from negative values of $\gamma$. Although the doughs exhibited some differences during the heating test, these differences were not significant during the initial and final phase of the test. The only significant $(p<0.05)$ differences were found during the gelatinization phase in which dough from AF Jumiko variety exhibited reduced gelatinization extent (0.09 Nm. $\mathrm{min}^{-1}$ ) than dough from Skorpion variety 
$\left(0.48 \mathrm{Nm} \cdot \mathrm{min}^{-1}\right)$. The differences in gelatinization rate among the other doughs were not significant.

\section{CONCLUSION}

The fine flours and doughs prepared from wheat grains with purple pericarp (PS Karkulka and Jumiko varieties), along with wheat grain with blue aleurone (Skorpion variety) were tested and compared with commercial flour to evaluate the applicability of colored grain wheat in bread making. The flours prepared from colored wheat grains exhibited variations in the values of Hagberg falling number and Zeleny sedimentation volume. The dough behavior during uniaxial deformation, farinographic and heating tests also varied. The differences were, however, generally weak. None of the tested colored wheat grain exhibited characteristics completely different from the others or the commercial one. The results may indicate the applicability of all tested colored wheat grains in bread making. Experimental baking tests, however, are yet to be performed to finally confirm it.

\section{REFERENCES}

Borrelli, G., Trono, D. 2016. Molecular approaches to genetically improve the accumulation of health-promoting secondary metabolites in staple crops - A case study: The Lipoxygenase-B1 genes and regulation of the carotenoid content in pasta products. International Journal of Molecular Sciences, vol. 17, no. 7, p. 1177. https://doi.org/10.3390/ijms17071177

Burešová, I., Hřivna, L. 2011. Effect of wheat gluten proteins on bioethanol yield from grain. Applied Energy, vol. 88, no. 4, p. 1205-1210. https://doi.org/10.1016/j.apenergy.2010.10.036

Collar, C., Bollain, C., Rosell, C. M. 2007. Rheological behavior of formulated bread doughs during mixing and heating. Food Science and Technology International, vol. 13, no. 2, p. 99-107. https://doi.org/10.1177/1082013207078341

ČSN EN ISO 3093: 2011. Wheat, rye and their flours, durum wheat and durum wheat semolina - Determination of the falling nuber according to Hagberg-Perten. Praha, Czech Republic : Czech Office for Standards, Metrology and Testing. ČSN EN ISO 5529: 2011. Wheat - Determination of the sedimentation index - Zeleny test. Praha, Czech Republic : Czech Office for Standards, Metrology and Testing.

Decree No. 333/1997 of Czech Republic. Part 111/1997 Coll. [online] s.a. [cit.2019-01-21] Available at: https://www.zakonyprolidi.cz/cs/1997-333

FAO. 2014. Wheat - the largest primary commodity. [online] s.a. [cit.2019-01-28] Available at: http://www.fao.org/resources/infographics/en/?topics=223489 \&topicslbl=Crops $\% 20$ and $\% 20$ varieties $\% 20$ for $\% 20$ the $\% 20 \mathrm{im}$ provement $\% 20$ of $\% 20$ food $\% 20$ security

Ficco, D. B. M., De Simone, V., De Leonardis, A. M., Giovanniello, V., Del Nobile, M. A., Padalino, L., Lecce, L., Borrelli, G. M., De Vita, P. 2016. Use of purple durum wheat to produce naturally functional fresh and dry pasta. Food

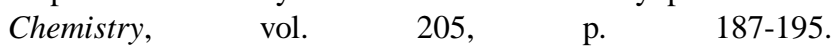
https://doi.org/10.1016/j.foodchem.2016.03.014

Goesaert, H., Brijs, K., Veraverbeke, W. S., Courtin, C. M., Gebruers, K., Delcour, J. A. 2005. Wheat flour constituents: how they impact bread quality, and how to impact their functionality. Trends in Food Science and Technology, vol. 16, no. 1-3, p. 12-30. https://doi.org/10.1016/j.tifs.2004.02.011

Kurt, A. R., Evers, A. 2017. Kent's technology of cereals. 5th ed. Cambridge, UK : Woodhead Publishing, 924 p. ISBN: 9780081005323.

Lachman, J., Hejtmánková, A., Orsák, M., Popov, M., Martinek, P. 2018. Tocotrienols and tocopherols in coloredgrain wheat, tritordeum and barley. Food Chemistry, vol. 240, p. 725-735. https://doi.org/10.1016/j.foodchem.2017.07.123

Martinek, P., Šorpík, M., Chrpová, J., Fučík, P., Schweiger, J. 2013. Development of the new winter wheat variety Skorpion with blue grain. Czech Journal of Genetics and Plant $\begin{array}{lllll}\text { Breeding, vol. 49, no. 2, p. 90-94. } & \end{array}$ https://doi.org/10.17221/7/2013-CJGPB

Mondal, A., Datta, A. K. 2008. Bread baking - a review. Journal of Food Engineering, vol. 86, no. 4, p. 465-474. https://doi.org/10.1016/j.jfoodeng.2007.11.014

Pasqualone, A., Bianco, A. M., Paradiso, V. M., Summo, C., Gambacorta, G., Caponio, F., Blanco, A. 2015. Production and characterization of functional biscuits obtained from purple wheat. Food Chemistry, vol. 180, no. 1, p. 64-70. https://doi.org/10.1016/j.foodchem.2015.02.025

Ranken, M. D., Kill, R. C., Baker, C. 1997. Food industries manual. LONDON, UK: Chapman \& Hall, 718 p. ISBN: 0751404047.

Tsiami, A. A., Bot, A., Agterof, W. G. M. 1997a. Rheology of mixtures of glutenin subfractions. Journal of Cereal Science, vol. 26, no. 3, p. 279-287. https://doi.org/10.1006/jcrs.1997.0131

Tsiami, A. A., Bot, A., Agterof, W. G. M., Groot, R. D. 1997b. Rheological properties of glutenin subfractions in relation to their molecular weight. Journal of Cereal Science, vol. 26, no. 1, p. 15-27. https://doi.org/10.1006/jcrs.1996.0104

\section{Acknowledgments:}

The authors thank Mr. David Bureš (david.bures01@upol.cz) from Palacký University Olomouc, Department of English and American Studies, Czech Republic, for translation and proofreading and Agrotest fyto, s.r.o Kroměříž, Czech Republic for providing samples for this research.

\section{Contact address:}

*Iva Burešová, Tomas Bata University in Zlín, Faculty of Technology, Department of Food Technology, nám. T. G. Masaryka 5555, 76001 Zlín, Czech Republic, Tel.: +420576033333, E-mail: buresova@utb.cz

Václav Trojan, Mendel University, Faculty of AgriSciences, Department of Plant Biology, Zemědělská 1, 61300 Brno, Czech Republic, Tel.: +420545133389, Email: vaclav.trojan@mendelu.cz

Martin Helis, Tomas Bata University in Zlín, Faculty of Technology, Department of Food Technology, nám. T. G. Masaryka 5555, 76001 Zlín, Czech Republic, Tel.: +420576033333, E-mail: m1_helis@utb.cz

Corresponding author: * 